\title{
Impacts of hydrology and hydropower on water quality in reservoir tailwaters
}

\author{
S. Ashby \\ US Army Engineer Research and Development Center, Vicksburg, USA
}

\begin{abstract}
Reservoirs alter riverine dynamics and can impact the water quality of the natural system. As demands for surface water supplies and hydropower increase, understanding the potential changes to riverine systems with construction and operation of dams is critical for decision-making in river basin management. This paper will utilize information from selected case studies to 1) overview the impacts of dams on river hydrology and water quality, and 2) provide tools used to mitigate impacts. For example, major changes to the natural hydrograph (e.g., dampening of storms, flow fluctuations associated with hydropower) will be summarized using examples of alterations to the downstream floodplain and channel hydrology and tools used in restoration actions. Changes in water quality in reservoir releases associated with retention and outlet works (e.g., temperature modifications, decreases in dissolved oxygen, and mobilization of nutrients and metals) will be reviewed. Case studies are used to describe downstream dissolved oxygen dynamics such as sag and recovery and associated impacts on the kinetics of nutrients and metals. Transport, oxidation kinetics, and fate of dissolved nitrogen species (ammonia and nitrate) and metals (iron and manganese) are summarized using data from field and laboratory studies. Techniques such as selective withdrawal, aeration, oxygenation, and use of weirs to mitigate water quality impacts are presented. Lastly, effects throughout the river system associated with multiple reservoirs (e.g. heat budgets and water supply) are discussed.
\end{abstract}

Keywords: dams, reservoirs, tailwaters, water quality.

\section{Introduction}

The construction of a dam and subsequent impoundment of the river result in altered hydrology, increased retention, and associated changes in water quality. 
Changes in water quality in the reservoir are often reflected in the releases and downstream reach, or tailwater region. Water quality impacts include varied temperature and dissolved oxygen concentrations, altered nutrient concentrations, and increased concentrations of redox-sensitive metals such as iron and manganese. Often, these changes are related to operation of the dam, e.g., releases for hydropower, minimum flow, and flood damage reduction. Additionally, the outlet works at dams can vary from surface withdrawal to bottom withdrawal, and combined outlet works such as tainter gates, penstocks, and selective withdrawal intakes. Operation of outlet works and seasonal changes in water quality of the reservoir (i.e., due to stratification) result in dynamic water quality conditions in the downstream area or tailwater. Multiple impoundments also impact hydrology and water quality in the river system. Increased demands on water for multiple purposes has heightened awareness of the availability and quality of surface waters, illustrates the potential for conflict, and the importance of informed decision-making in river basin management. Poff et al. [1] provide a good synopsis of water allocation issues in rivers associated with anthropogenic hydrologic alterations and point out the financial investments society is willing to make to provide acceptable river basin management.

\section{Changes in river hydrology}

One of the major changes in river hydrology when a dam is constructed is deviation from the normal hydrograph. Without the impoundment, the hydrograph responds to inflow events and low flow periods when there is little runoff (Figure 1A). With an impoundment in place, the hydrograph is often modified to reduce peak flows and augment low flow periods with a minimum flow release regime (Figure 1B). The response downstream includes decreased energy that changes material transport, river morphology, and habitat for aquatic biota and vegetation. Changes in floodplain interactions also occur and can alter spawning and rearing patterns for fish and germination and seedling development for riparian vegetation. Declines in riparian cottonwood have been attributed to altered hydrology (Williams and Cooper [2]). Hauer and Lorang [3] have demonstrated changes in community structure in a regulated river associated with hydrologic alterations and changes in river bed morphology and interactions between surface water and groundwater. River basin managers are now modifying release schedules from dams to return to a more natural hydrograph recognized as environmental flows. These modifications typically consist of pulsed releases in the spring and more fluctuation during periods of minimum flow. Changes in flow are a function of water availability and are often considered in the context of annual conditions (e.g., wet years and dry years). Release regimes are also developed in consultation with regional ecological experts to determine optimal delivery features for biota. 


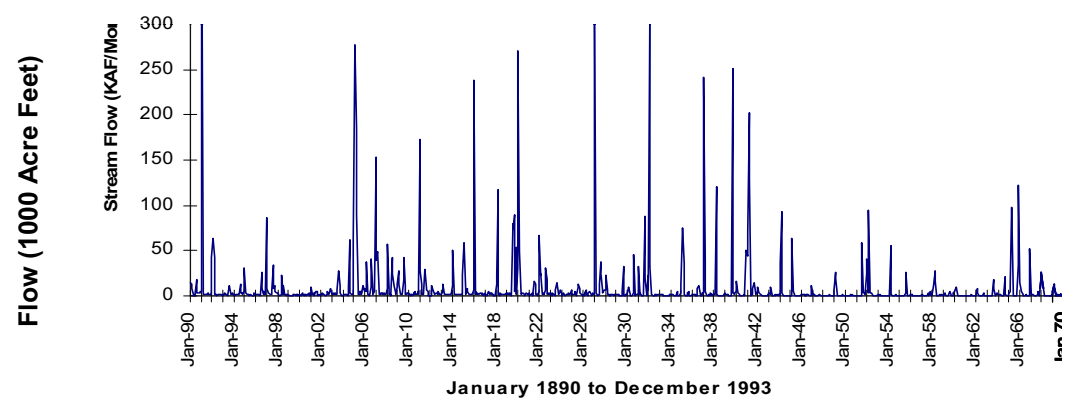

A

Historic (Pre-Dam) Stream Flows

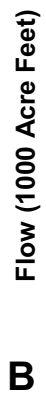

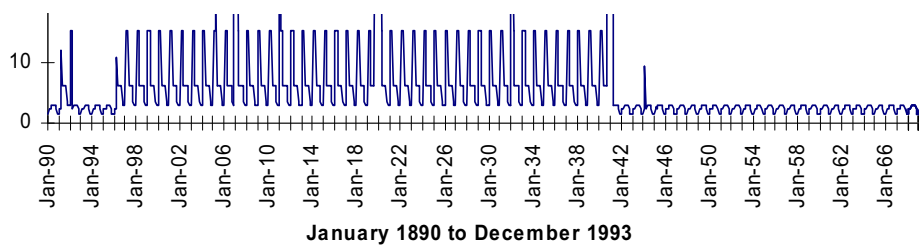

Monthy HEC-PRM Releases Based Strictly on Riparia

Time

Figure 1: Representative hydrographs without (A) and with (B) an impoundment on a river.

\section{Changes in water quality}

Changes in water quality occur with the impoundment of a river and resultant reservoir. Increased residence time can result in the development of thermal stratification and density gradients in the impoundment. These density gradients result in a vertical structure that affects inflow patterns, internal circulation, and vertical profiles at the outlet structures. Often, isolation of deeper waters occurs on a seasonal basis. Under these conditions, oxygen consumption by biota exceeds oxygen production via photosynthesis and exchange with atmospheric oxygen and hypoxic and anoxic conditions can occur (Figure 2). As dissolved oxygen concentrations decrease, chemical changes occur and nutrients and metals are mobilized from the sediments and are available for release downstream. Major changes in water quality are associated with oxidation and reduction forms of nutrients (e.g., nitrate and ammonia), metals (e.g., iron and manganese), and interactions between nutrients and metals (e.g., phosphorus and iron). Reaeration often occurs as water is released from the impoundment and reduced forms of nutrients and metals are oxidized. 


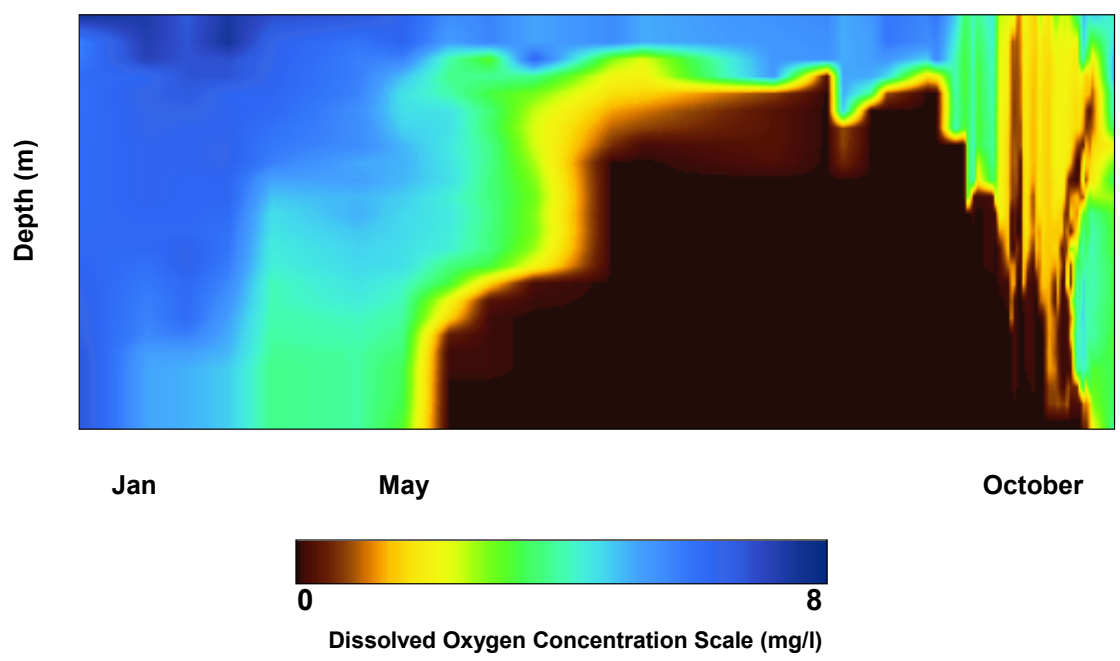

Figure 2: Temporal and vertical distribution of dissolved oxygen in a stratified impoundment.

As illustrated in Figure 2, vertical gradients in water quality result in different concentrations available to release waters. Temperature and the concentrations of chemical constituents in release waters are also functions of the outlet works. Typically, outlet works provide releases from mid-depth to near bottom for hydropower (Figure 3), bottom (Figure 4) or surface (Figure 5), and from multiple depths with a selective withdrawal structure (Figure 6). Often, the type of outlet structure can be used for management of water quality.

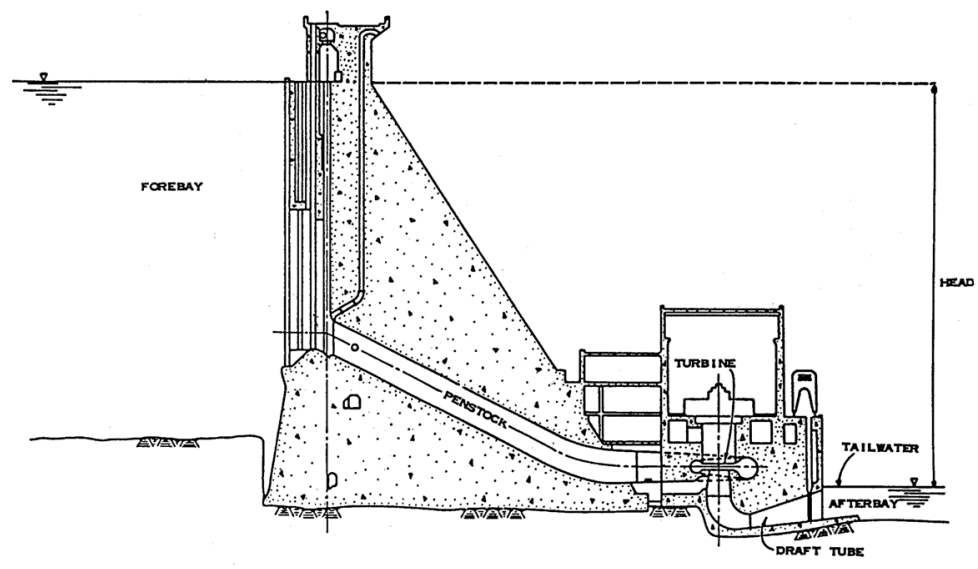

Figure 3: Representative hydropower release outlet structure in a dam. 


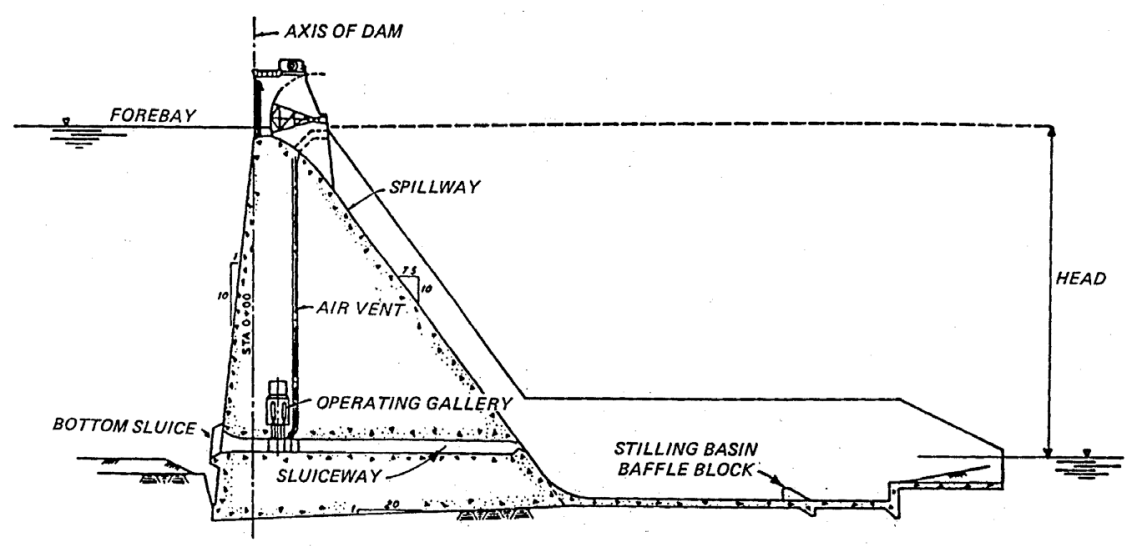

Figure 4: Representative bottom release outlet structure in a dam.

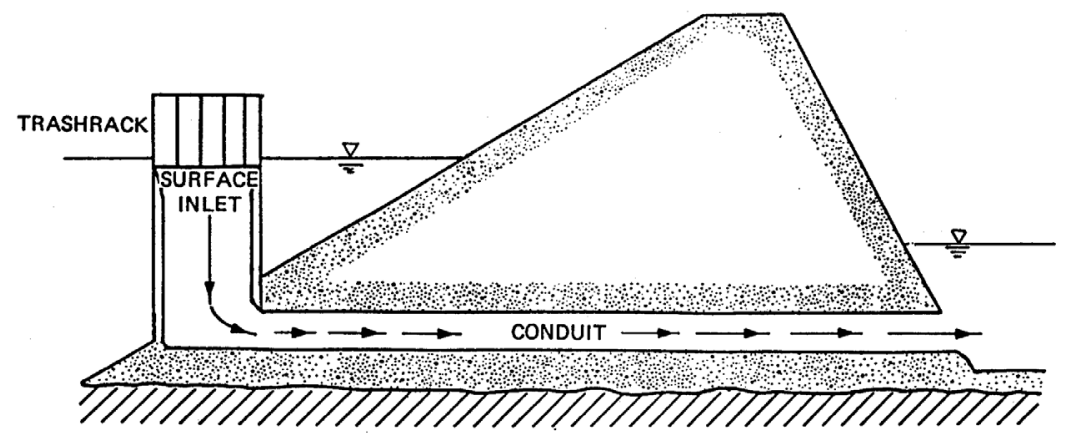

Figure 5: Representative surface release outlet structure in a dam.

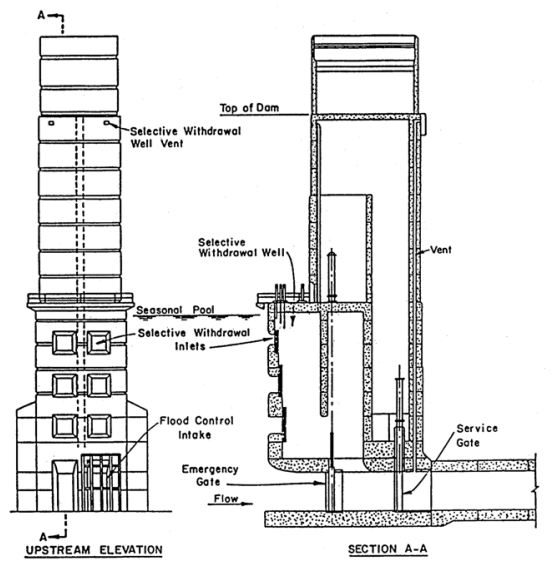

Figure 6: Representative selective withdrawal outlet structure in a dam. 
As water is released from dams, reaeration can occur in association with discharge features of the dam (e.g., turbine venting at hydropower projects or physical entrainment of atmospheric gases through gated structures), through turbulence, and phytoplankton productivity in the tailwater and downstream area (Figure 7). Longitudinal distribution of concentrations also varies with discharge (Figure 8). Longitudinal distribution of total concentrations of selected chemical species is often a function of oxidation states and dissolved and particulate forms. For example, changes in dissolved oxygen also provide for the conversion of ammonia to nitrate (Figure 8). Ammonia concentrations decrease as conversion to nitrate-nitrite nitrogen occurs and concentrations of nitratenitrite nitrogen increase. Under conditions of low discharge, conversion of ammonia to nitrate-nitrite nitrogen occurs closer to the point of discharge. Similar patterns have been observed for the oxidation of reduced (e.g., dissolved) iron to oxidized or particulate forms (Ashby et al. [4]). Particulate iron is transported as a floc and eventually settles as a function of flow. The settled floc can be resuspended as flows increase (e.g., during hydropower releases) and result in an increase in turbidity (Figure 9) and downstream concentrations of total iron (Figure 10) (Ashby et al. [5]). Impacts of hydropower releases have also been observed in association with peaking operations (Ashby et al. [6]). Dissimilarly, dissolved manganese removal has been shown to be associated with microbial processes (Ashby and Gambrell [7]) and downstream concentrations can remain relatively unchanged for great distances during hydropower releases (Figure 10). Under conditions suitable for microbial removal of dissolved oxygen (e.g., low flow, suitable temperatures, and presence of bottom substrate) concentrations can decrease much more rapidly (e.g., hours) (Ashby and Gambrell [7]).

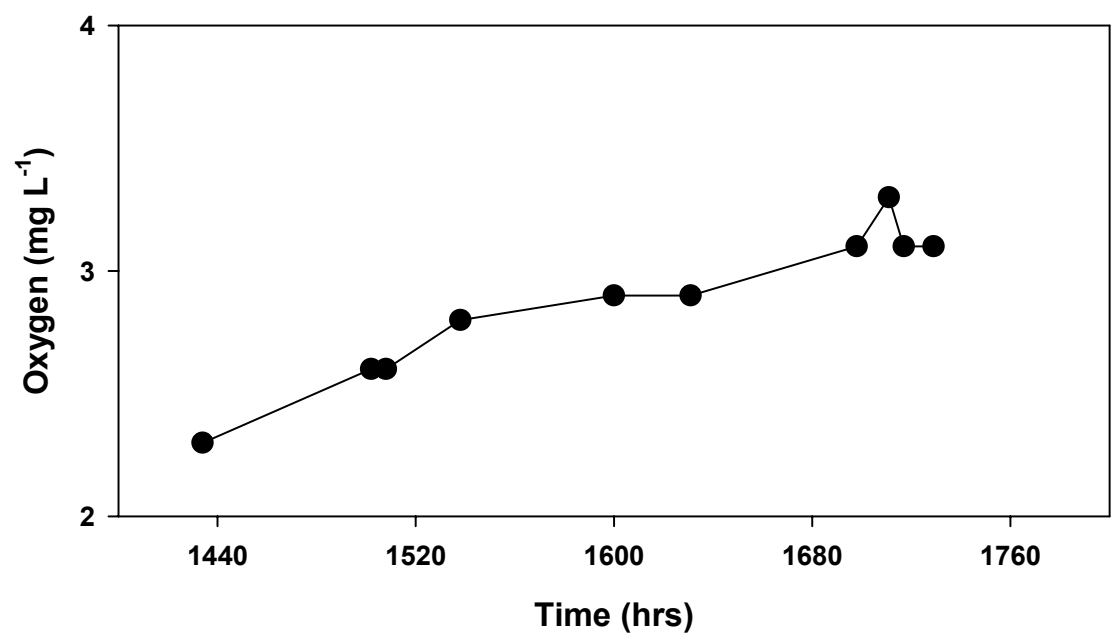

Figure 7: Dissolved oxygen recovery downstream from a hydropower dam. 

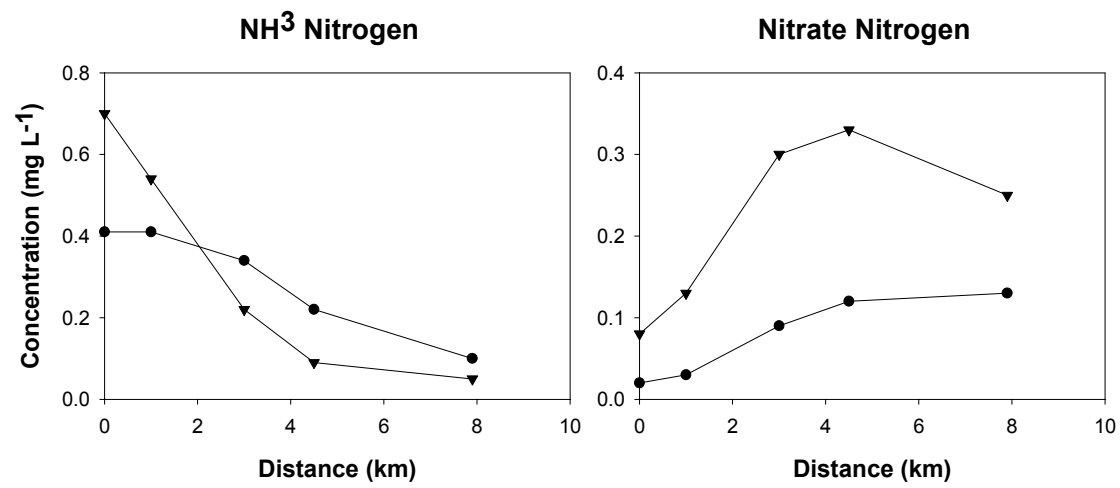

$$
\begin{aligned}
& \longrightarrow \text { High Flow } \\
& \longrightarrow \text { Low Flow }
\end{aligned}
$$

Figure 8: Longitudinal distribution of ammonia and nitrate-nitrite concentrations in a tailwater during a low flow and a high flow release.

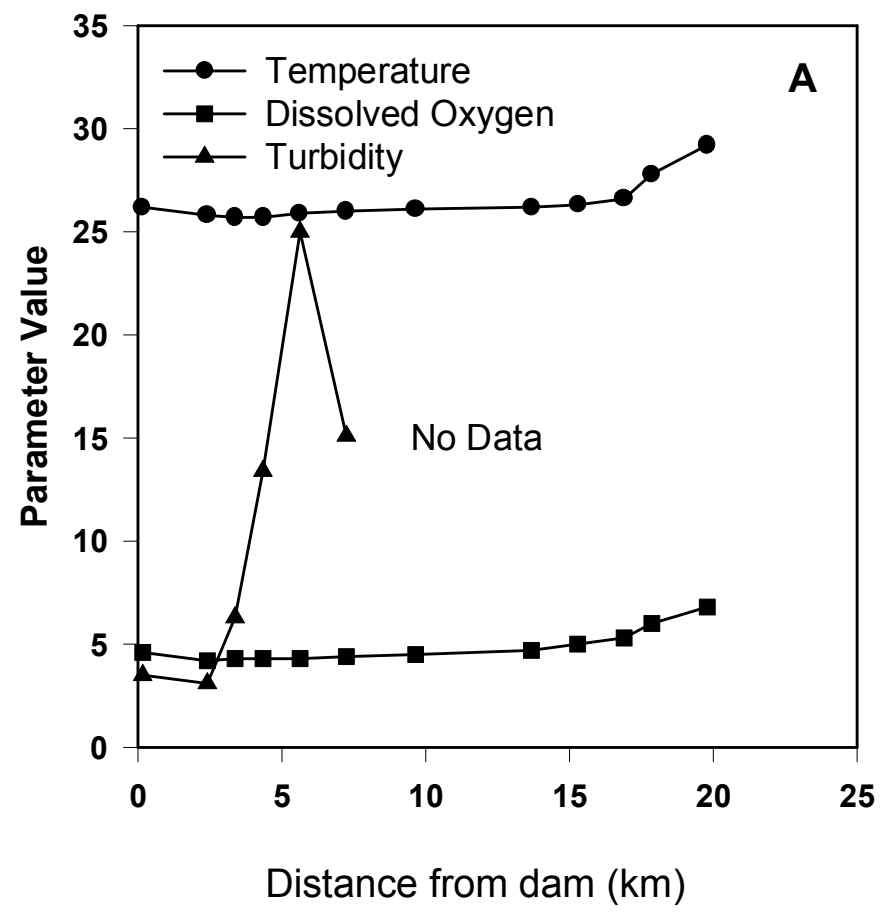

Figure 9: Longitudinal distribution of turbidity in the tailwater of a hydropower release. 


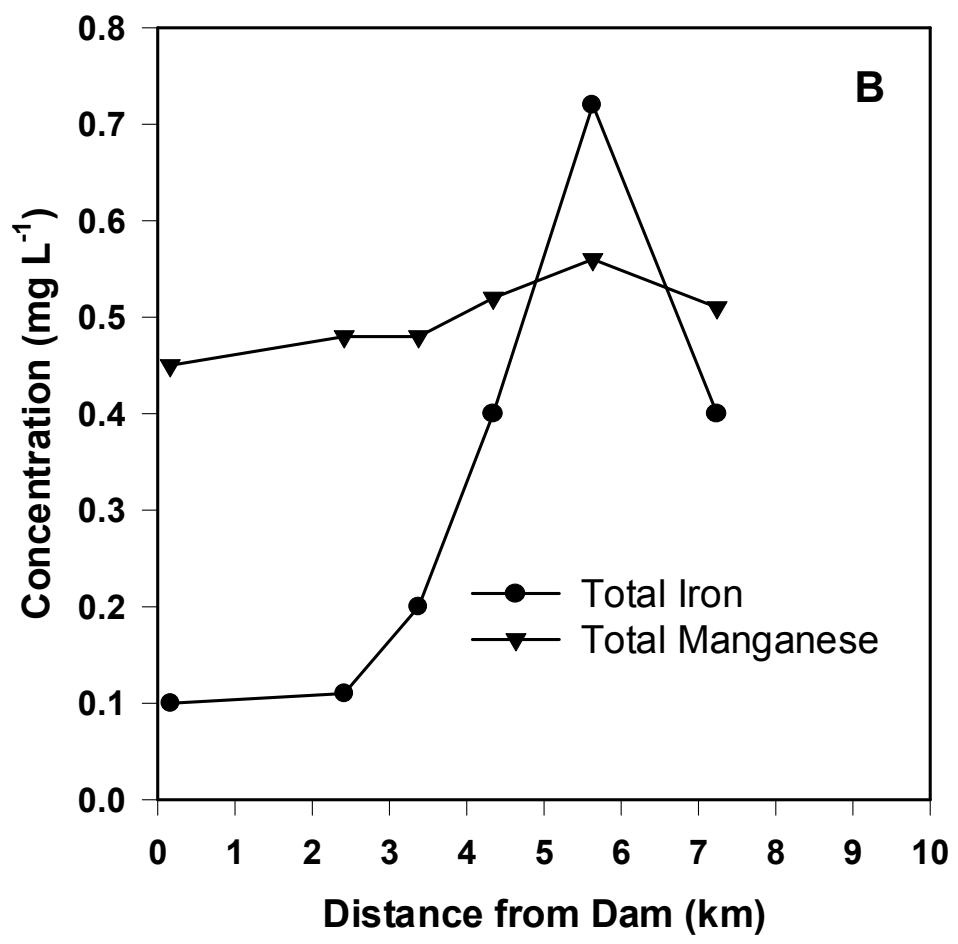

Figure 10: Longitudinal increase in total iron and total manganese in the tailwater of a hydropower release.

\section{Water quality management techniques}

Management techniques to improve water quality in tailwaters are most often applied as 1) in-reservoir techniques such as mixing, aeration (Figure 11), or oxygenation or 2) tailwater techniques such as diffusive weirs (Figure 12). For hydropower operations, turbine venting has also been successfully applied. The cost for each of these techniques varies and can be relatively expensive. Other methods to improve water quality in releases from dams include selective withdrawal (when possible) and combined releases such as spilling of surface water in combination with bottom withdrawals. When changes in discharge (or operational rule curves) are possible, improvements in downstream habitats may be accomplished by returning to a more natural hydrograph. Watershed management techniques are also used but require a long time period for water quality improvements in impoundments. This is especially true where internal loading of nutrients and metals can continue as seasonal hypoxic and anoxic conditions occur. A working summary of water quality management techniques for reservoirs and tailwaters has been compiled by Wilhelms and Ashby [8] and is most applicable for larger dams. 


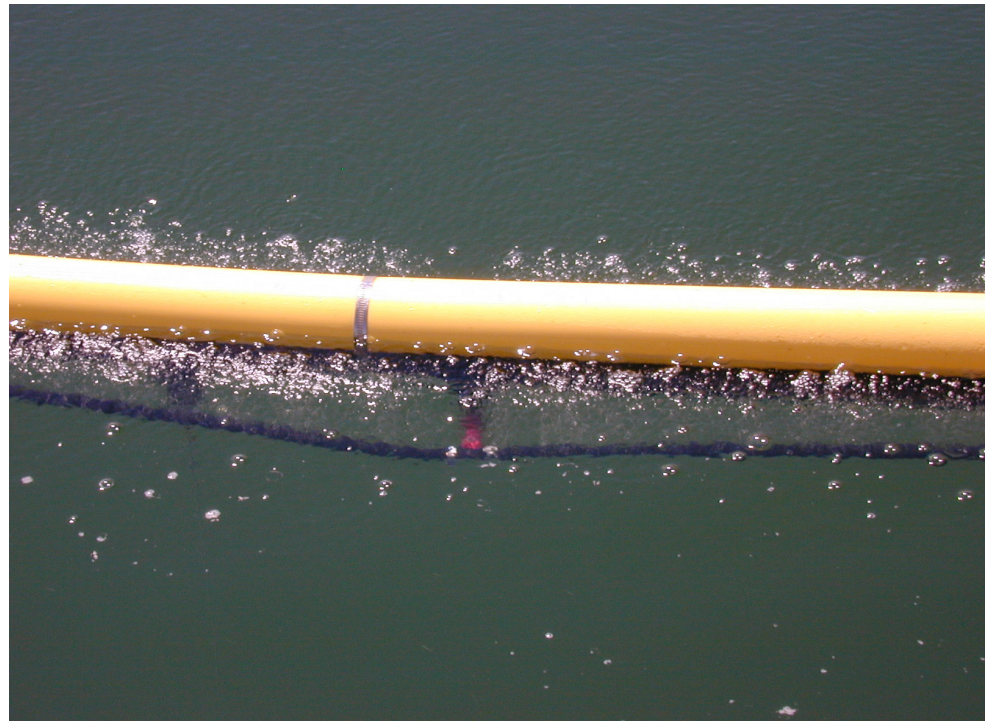

Figure 11: Segment of oxygenation system for in-reservoir deployment.

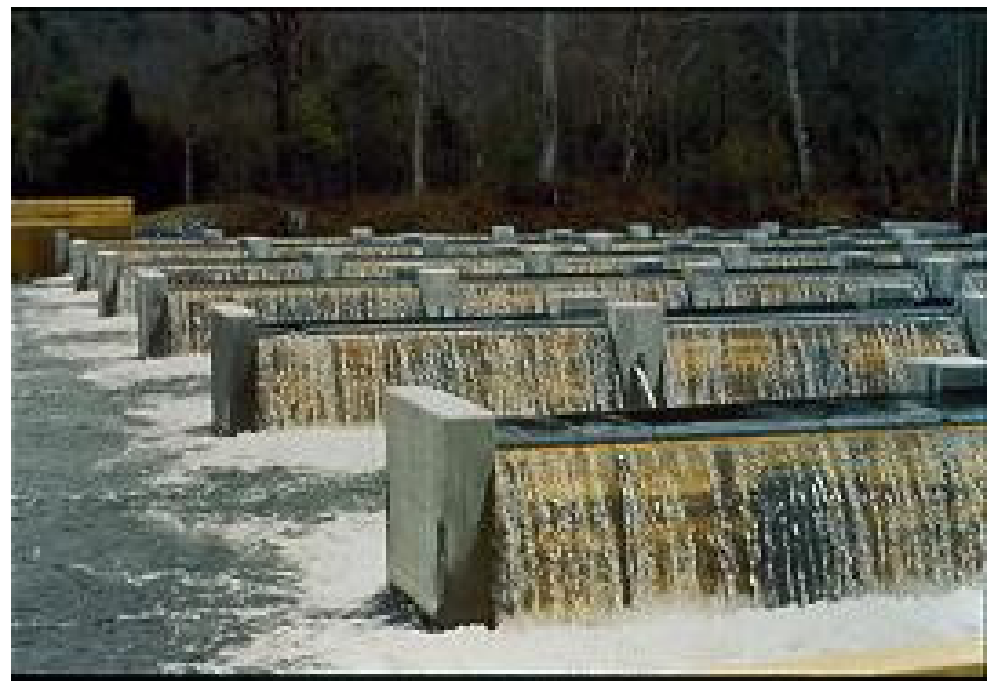

Figure 12: Diffusive weir in a tailwater. 


\section{Effects of multiple impoundments in a river basin}

The presence of multiple impoundments in a river basin can result in cumulative effects such as changes in heat budgets and temperature regimes, changes in sediment budgets and river geomorphology, and changes in nutrient availability. All of these effects impact the quality and quantity of habitat. For example, the addition of an impoundment (Richard B. Russell (RBR)) on the Savannah River in the United States has resulted in a decrease in annual loading to the river and downstream impoundments (Figure 13). After the construction of the RBR Dam, Savannah River phosphorus loadings decreased to less than half of the load available downstream (Figure 14). Loading from the Broad River, a major

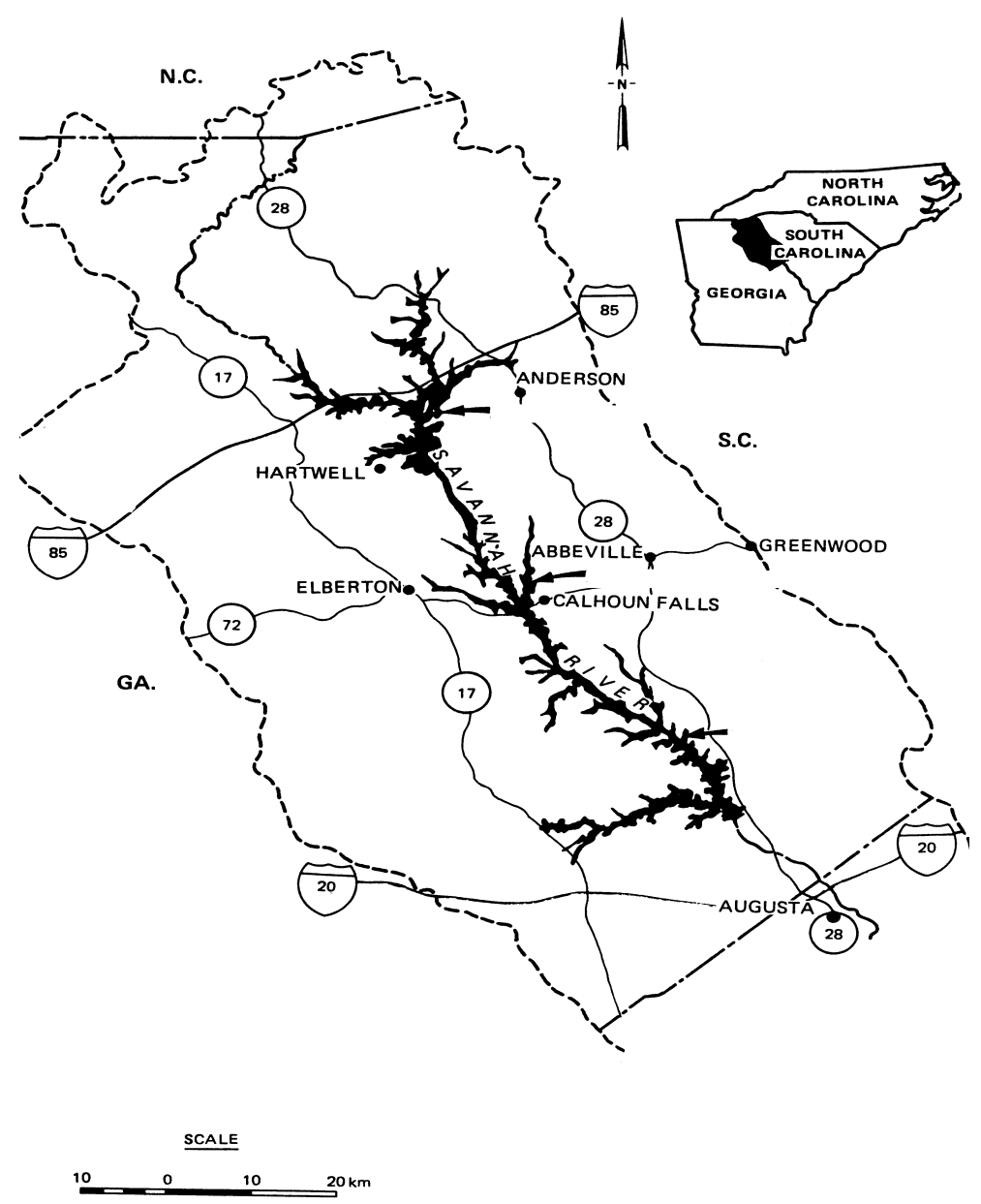

Figure 13: Multiple impoundments on the Savannah River, USA. 
tributary to the Savannah River downstream of RBR, while previously nearly equal in contribution when compared to the Savannah River, is now the major source of phosphorus to the system. River basin management activities need to account for changes in sources. With increased retention of phosphorus as the result of the construction of the RBR Dam, watershed management activities can be focused on the watershed of the Broad River.

Impacts on aquatic resources also need to be assessed in conjunction with changes in water quality associated with the construction of multiple impoundments. For example, another major impoundment is located immediately downstream from the RBR Dam and the greatly reduced phosphorous load which can impact phytoplankton productivity and trophic dynamics. While changes in nutrient loadings were not an initial consideration, construction of the RBR Dam did consider impacts on the river's fisheries and impacts of hydropower on downstream water quality. A desire to maintain temperatures acceptable for trout habitat required release of bottom waters that were very likely to have low concentrations of dissolved oxygen. A hypolimnetic oxygenation system was installed to provide dissolved oxygen concentrations suitable for trout habitat.

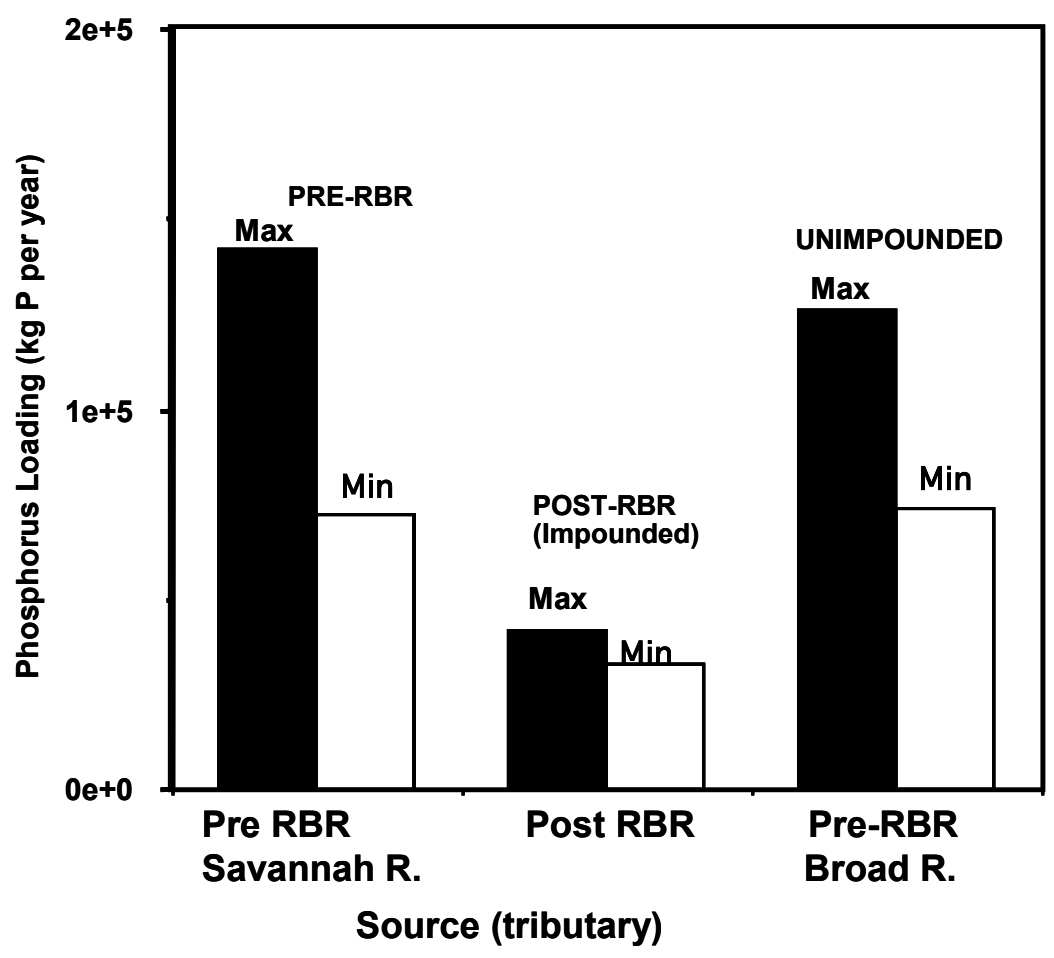

Figure 14: Comparisons of annual phosphorus loading with and without construction of another impoundment on the Savannah River, USA. 


\section{Summary and conclusions}

Construction of impoundments alters the natural hydrology and hydraulics in river basins, effects changes in water quality, and impacts aquatic and riparian habitat. Downstream water quality and habitats are also impacted by reservoir operations, particularly for hydropower projects. Water quality management techniques applied in the reservoir, associated with reservoir operations, and in the tailwater are most effective for river basin management. Application of management techniques should be considered using a systems approach when multiple impoundments exist or are being considered for development in a river basin.

\section{Acknowledgements}

This work was conducted as an activity of the Water Quality Research Program, US Army Corps of Engineers (USACE). Permission was granted by the Chief of Engineers to publish this information.

\section{References}

[1] Poff, L., Allan, J.D, Palmer, M.A., Hart, D.D., Ricther, B.D., Arthington, A.H., Rogers, K.H., Meyer, J.L., and Stanford, J.A. River flows and water wars: emerging science for environmental decision making. Front Ecol Environ, 1(6): pp. 298-306, 2008.

[2] Williams, C.A. and Cooper, J.D. Mechanisms of riparian cottonwood decline along regulated rivers. Ecosystems, 8: pp. 382-395, 2005.

[3] Hauer, R.F., and Lorang, M.S. River regulation, decline of ecological resources, and potential for restoration in semi-arid lands river in the western USA. Aquatic Sciences, 66: pp.1-14, 2004.

[4] Ashby, S.L., Faulkner, S.P., Gambrell, R.P, and Smith, B.A. Assessing iron dynamics in reservoir releases. Lake and Reservoir Management, 20(1): pp. 65-75, 2004.

[5] Ashby, S.L., Myers, J.L., Laney, E., Honnell, D., and Owens, C. Effects of Hydropower Releases from Lake Texoma on Downstream Water Quality. $J$. of Freshwater Ecology, 14(1): pp.103-112.

[6] Ashby, S. L., Kennedy, R.H, and Jabour, W.E. Water quality dynamics in the discharge of a southeastern hydropower reservoir: Response to peaking generation operation. Lake and Reservoir Management, 11(3): pp.209-215.

[7] Ashby, S.L. and Gambrell, R.P. Manganese removal in reservoir releases: influence of biological and hydrodynamic processes, in Proceedings of the $7^{\text {th }}$ International Symposium on Ecohydraulics, Concepcion, Chile. 2009.

[8] Wilhelms, S. and Ashby, S. (Eds). The WES Handbook on Water Quality Enhancement Techniques for Reservoirs and Tailwaters, U.S. Army Corps of Engineers, Waterways Experiment Station, Vicksburg, MS, USA. https://swwrp.usace.army.mil/_swwrp/swwrp/4-Pubs/WaterQualityRpts/ WaterQualityHandbook.pdf 